\title{
PERSEPSI MAHASISWA PROGRAM D III KEPERAWATAN UMM TERHADAP MANFAAT ASUHAN KEPERAWATAN KELUARGA DALAM MENINGKATKAN SKILL PRAKTEK LAPANGAN
}

\author{
Perception of Nursing Student Program D III Umm Benefit of Nursing Skills In Improving \\ Family Practice Field \\ Reni Ilmiasih \\ Program Studi Diploma III Keperawatan Fakultas Ilmu Kesehatan Universitas Muhammadiyah Malang \\ Jl. Bendungan Sutami 188A Malang 65145 \\ e-mail: umar.maksum@yahoo.co.id
}

\begin{abstract}
ABSTRAK
Profesi keperawatan merupakan bentuk pelayanan profesional yang menyadari sepenuhnya tentang keberadaan keluarga. Karena menyadari kompleknya masalah keluarga, maka diperlukan persepsi positif mahasiswa tentang ilmu keperawatan. Berdasarkan hasil laporan mahasiswa praktek keperawatan di Puskesmas, ada sebagian mahasiswa yang melalaikan tugas pembuatan asuhan keperawatan keluarga karena persepsi yang kurang tepat terhadap manfaat asuhan keperawatan keluarga sehingga perlu dilakukan strategi khusus untuk meluruskan persepsi tersebut. Tujuan Penelitian ini untuk mengetahui persepsi mahasiswa program D III Keperawatan UMM terhadap manfaat asuhan keperawatan keluarga dalam meningkatkan skill praktek lapangan. Desain penelitian menggunakan deskriptif kuantitatif. Sampelnya adalah mahasiswa semester VI angkatan 2003/2004 sebanyak 40 mahasiswa dengan menggunakan accidental sampling. Analisa data dengan standar skala Guttman dan prosentase jumlah. Hasil penelitian didapatkan persepsi mahasiswa terhadap indikator pemahaman asuhan keperawatan keluarga 58\% persepsi positif. Sedangkan persepsi mahasiswa terhadap indikator manfaat asuhan keperawatan keluarga dalam meningkatkan pengetahuan didapatkan $65 \%$ persepsi positif. Persepsi negatif didapatkan pada indikator pengetahuan terhadap skill praktek lapangan sebesar 55\% dan indikator manfaat asuhan keperawatan keluarga dalam meningkatkan skill praktek lapangan 52\%. Kesimpulan dari hasil penelitian didapatkan persepsi positif mahasiswa pada pemahaman dan manfaat asuhan keperawatan keluarga, serta persepsi negatif mahasiswa pada manfaat asuhan keperawatan keluarga dalam meningkatkan skill. Dari hasil di atas disarankan kepada pembimbing untuk pengarahan yang lebih intensif agar setiap mahasiswa mempunyai persepsi yang baik terhadap kompetensi skill yang dicapai dalam praktek asuhan keperawatan keluarga.
\end{abstract}

Kata kunci: persepsi, asuhan keperawatan keluarga, skill

\begin{abstract}
Nursing profession is a form of professional service that is fully aware of the existence of the family. Because a completely aware of family problems, it can take a positive perception of nursing students. Based on the results reported in the nursing practice student health center, there are some students who fail the task of creating a family nursing process because of lack of proper perception of the benefits of family nursing process so that specific strategies need to be done to correct these perceptions. The purpose of this study to determine student perceptions of Nursing Diploma UMM of family nursing process benefits increase skill in practice field. Descriptive research design was quantitative. Sample is sixth semester students force 2003/2004. The number of samples of 40 students is with accidental sampling technique of sampling. With data analysis standard of the Guttman scale and percentage amount. The results obtained for indicators of student perceptions of understanding of family nursing process 58\% positive perceptions. Meanwhile, student perceptions of indicators of family nursing process benefits in improving the knowledge acquired $65 \%$ positive perceptions. Negative perceptions of knowledge gained on the indicator to the practice field skills by 55\%, and indicators of family nursing process benefits in improving the practice field skills (52\%). Conclusion of research result got by positive perception of student at upbringing benefit and understanding treatment of family, and also negative perception of student at upbringing benefit treatment of family in improving skill. From the results above suggested to
\end{abstract}


the supervisor for more intensive guidance so that each student has a good perception of the achieved skill competency in the practice of family nursing process.

Keywords: perception, family nursing process, skill

\section{LATAR BELAKANG}

Keluarga merupakan bagian terkecil dari kelompok masyarakat yang sangat penting untuk mendapat perhatian. Banyak masalah yang dihadapi induvidu berawal dari keluarga dan keluarga sendiri juga mempunyai potensi untuk menyelesaikan masalah yang dihadapi oleh anggota keluarganya, tetapi tidak semua keluarga mampu mengatasi segala permasalahan dengan tepat.

Profesi keperawatan merupakan bentuk pelayanan profesional yang menyadari sepenuhnya tentang keberadaan keluarga. Sesuai dengan definisi keperawatan bahwa tujuan dari pelayanan keperawatan salah satunya adalah keluarga (Lokakarya Nasional Keperawatan, 1983). Dalam perkembangan ilmu keperawatan sendiri, keluarga mendapat perhatian yang cukup besar. Karena menyadari kompleknya masalah keluarga, maka ilmu keperawatan keluarga yang bergabung dengan ilmu keperawatan komunitas sekarang sudah menjadi cabang ilmu tersendiri. Dalam ilmu keperawatan keluarga tersebut membahas tentang teori keluarga dan asuhan keperawatan keluarga.

Berdasarkan hasil laporan mahasiswa praktek keperawatan di Puskesmas, ada sebagian mahasiswa yang melalaikan tugas pembuatan asuhan keperawatan keluarga dengan berbagai alasan diantaranya adalah anggapan kurang merasakan adanya manfaat pemberian asuhan keperawatan pada keluarga. Dari 96 mahasiswa yang sudah mengumpulkan hasil laporannya didapatkan $50 \%$ data yang terkumpul kurang lengkap dan tidak valid serta dalam merumuskan masalah keperawatan kurang tepat meskipun sudah diberikan bimbingan (Hasil Laporan PKMD, 2006).
Kelalaian mahasiswa dalam pembuatan asuhan keperawatan keluarga dapat terjadi karena persepsi yang kurang tepat terhadap manfaat asuhan keperawatan keluarga sehingga perlu dilakukan strategi khusus untuk meluruskan persepsi tersebut. Salah satu cara dengan memperluas informasi mengenai masalah keperawatan keluarga dan alasan keluarga sebagai salah satu unit pelayanan kesehatan yang diantaranya menyebutkan bahwa keluarga dapat menimbulkan, mencegah, mengabaikan atau memperbaiki masalah-masalah kesehatan dalam kelompoknya (Freeman dalam Effendi, 1998). Informasi tersebut sebagai stimulus yang nantinya akan terproses labih lanjut sampai diterima dan dihasilkan persepsi yang diharapkan (Widatun, 1999). Sehingga mahasiswa mampu membuat dan melaksanakan asuhan keperawatan keluarga dengan penuh tanggung jawab dan bermanfaat bagi keluarga dan mahasiswa dalam meningkatkan skill praktek lapangan.

Tujuan penelitian ini untuk mengetahui persepsi mahasiswa program D III Keperawatan UMM terhadap manfaat asuhan keperawatan keluarga dalam meningkatkan skill praktek lapangan.

\section{METODE}

Desain penelitian yang digunakan adalah deskriptif kuantitatif dengan menggambarkan hasil penelitian berdasarkan prosentase jumlah. Penelitian ini dilaksanakan pada mahasiswa program D III Keperawatan Univeritas Muhammadiyah Malang semester VI angkatan 2003/3004, sejak bulan Juni sampai dengan November 2007.

Secara umum langkah-langkah dan sistematika penelitian terdapat dalam kerangka kerja pada skema 1 . 
Populasi dalam penelitian ini adalah mahasiswa program D III Keperawatan UMM semester VI yang telah melakukan praktek PKMD dengan sampel sejumlah 40 . Cara pengambilan sampel menggunakan teknik accidental sampling dengan membagikan kuesioner pada mahasiswa yang kebetulan ditemui pada saat supervisi bimbingan akhir PKMD.

\section{HASIL DAN PEMBAHASAN}

\section{Karakteristik Responden}

Hasil penelitian tentang karakteristik responden disajikan dalam tabel:

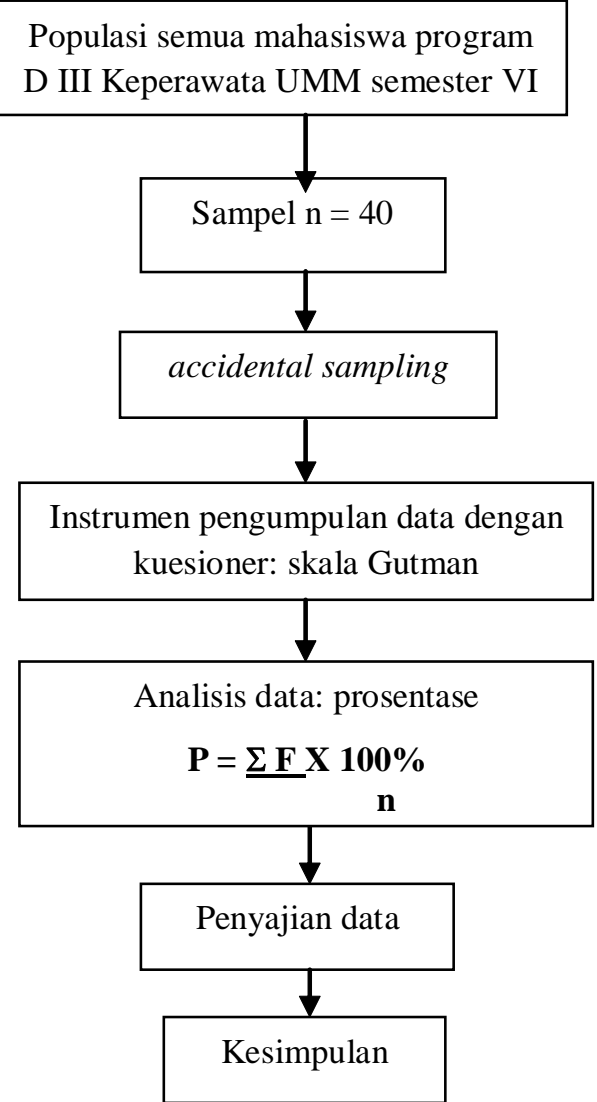

Gambar 1. Skema Kerangka kerja

Tabel 1. Distribusi frekuensi karakteristik responden berdasarkan jenis kelamin

\begin{tabular}{lccc}
\hline $\begin{array}{c}\text { Karakteristik } \\
\text { responden }\end{array}$ & $\begin{array}{c}\text { Maha } \\
\text { siswa }\end{array}$ & Total & Prosentase \\
\hline Jenis kelamin: & & & \\
a. Laki-laki & 14 & 40 & 35 \\
b. Perempuan & 26 & & 65 \\
\hline
\end{tabular}

Tabel 2. Distribusi frekuensi karakteristik responden berdasarkan umur

\begin{tabular}{lccc}
\hline $\begin{array}{c}\text { Karakteristik } \\
\text { responden }\end{array}$ & $\begin{array}{c}\text { Mahas } \\
\text { iswa }\end{array}$ & Total & Prosentase \\
\hline Umur: & & & \\
a. 15-20 Tahun & 29 & 40 & 73 \\
b. 20-35 Tahun & 11 & & 27 \\
\hline
\end{tabular}

\section{Indikator Persepsi Responden}

Hasil penelitian tentang indikator persepsi responden disajikan dalam tabel:

Tabel 3. Persepsi responden terhadap asuhan keperawatan keluarga

\begin{tabular}{llc}
\hline Indikator persepsi & $\begin{array}{c}\text { Juml } \\
\text { ah }\end{array}$ & $\begin{array}{c}\text { Prose } \\
\text { ntase }\end{array}$ \\
\hline 1. $\begin{array}{l}\text { Memahami manfaat askep } \\
\text { keluarga. } \\
\text { Tidak memahani manfaat } \\
\text { askep keluarga. }\end{array}$ & 23 & 58 \\
\hline \multicolumn{1}{c}{ Rata-rata keseluruhan } & 40 & 17 \\
\hline
\end{tabular}

Tabel 4. Persepsi responden terhadap manfaat asuhan keperawatan keluarga dalam meningkatkan pengetahuan

\begin{tabular}{llc}
\hline \multicolumn{1}{c}{ Indikator persepsi } & $\begin{array}{c}\text { Jum } \\
\text { lah }\end{array}$ & $\begin{array}{c}\text { Prose } \\
\text { ntase }\end{array}$ \\
\hline 1. $\begin{array}{l}\text { Merasakan manfaat dalam } \\
\text { meningkatkan pengetahuan } \\
\text { selama praktek. }\end{array}$ & 36 & 65 \\
2. & & \\
$\begin{array}{l}\text { Tidak merasakan adanya } \\
\text { peningkatkan pengetahuan } \\
\text { selama praktek. }\end{array}$ & 14 & 35 \\
\hline Rata-rata keseluruhan & 40 & 100 \\
\hline
\end{tabular}

Tabel 5. Persepsi responden terhadap skill praktek lapangan

\begin{tabular}{lcc}
\hline \multicolumn{1}{c}{ Indikator persepsi } & Jumlah & $\begin{array}{c}\text { Prosen } \\
\text { tase }\end{array}$ \\
\hline $\begin{array}{l}\text { 1. } \begin{array}{l}\text { Mengetahui indikator } \\
\text { skill praktek askep. }\end{array} \\
\text { 2idak mengetahui } \\
\text { indikator skill praktek } \\
\text { askep. }\end{array}$ & 22 & 45 \\
\hline Rata-rata keseluruhan & 40 & 100 \\
\hline
\end{tabular}


Tabel 6. Persepsi responden terhadap manfaat asuhan keperawatan keluarga dalam meningkatkan skill

\begin{tabular}{lcc}
\hline Indikator persepsi & $\begin{array}{c}\text { Jum } \\
\text { lah }\end{array}$ & $\begin{array}{c}\text { Prose } \\
\text { ntase }\end{array}$ \\
\hline 1. $\begin{array}{l}\text { Merasakan manfaat dalam } \\
\text { meningkatkan skill selama } \\
\text { praktek. }\end{array}$ & 19 & 48 \\
$\begin{array}{l}\text { 2idak merasakan manfaat } \\
\text { dalam meningkatkan skill } \\
\text { selama praktek. }\end{array}$ & 21 & 52 \\
\hline Rata-rata keseluruhan & 40 & 100 \\
\hline
\end{tabular}

\section{Indikator Persepsi Responden}

Yang dimaksud dengan persepsi mahasiswa terhadap manfaat asuhan keperawatan keluarga dalam meningkatkan skill di lapangan adalah meliputi pemahaman mahasiswa terhadap asuhan keperawatan keluarga, manfaat asuhan keperawatan keluarga dalam meningkatkan pengetahuan, persepsi mengenai skill praktek lapangan dan manfaat asuhan keperawatan keluarga dalam meningkatkan skill praktek lapangan.

Dari tabel 3 diketahui sebanyak 58\% mahasiswa memahami manfaat asuhan keperawatan keluarga. Hal ini dapat diartikan bahwa lebih dari separuh responden mempunyai persepsi positif terhadap pemahaman asuhan keperawatan keluarga. Hasil ini menunjukkan adanya perhatian atau perhatian mahasiswa dalam memahami teori asuhan keperawatn keluarga pada saat proses pembelajaran teori maupun proses pembelajaran praktek. Adanya atensi merupakan salah satu faktor yang mempengaruhi terjadinya persepsi seperti yang dikemukakan Widatun (1999).

Dari tabel 4 diketahui sebanyak $65 \%$ mengindikasikan adanya manfaat dalam meningkatakan pengetahuan, yang berarti juga merupakan persepsi positif. Persepsi positif tentang manfaat asuhan keperawatan keluarga dalam neningkatkan pengetahuan dapat terjadi karena cakupan asuhan keperawatan keluarga bukan hanya masalah penguasaan ketrampilan skill melainkan juga pada kemampuan pendekatan personal, pengetahuan budaya, karakter dan bentuk serta perkembangan keluarga. Dengan demikian mempelajari asuhan keperawatan keluarga secara tidak langsung dapat menambah pengetahuan segala aspek yang berkaitan dengan keluarga dan lingkungan sosial baik dalam teori pengkajian sampai dengan tindakan keperawatan seperti yang terjabarkan dalam buku teori dan praktek keperawatan keluarga (Friedman, 1998).

Dari tabel 5 diketahui sebanyak 55\% responden tidak mengetahui indikator pencapaiannya. Hal ini menunjukkan lebih dari separuh responden mempunyai persepsi negatif. Kurangnya pengetahuan mahasiswa tentang indikator skill praktek asuhan keperawatan dikarenakan perlu latihan dan memahami ketrampilan khusus dalam pelaksanaan asuhan keperawatan keluarga. Pelaksanaan ilmu keperawatan hanya dapat dilaksanakan oleh tenaga kesehatan yang mempunyai keahlian dan ketrampilan khusus, untuk itu semua pemberi pelayanan/asuhan keperawatan harus ditujukan untuk mencapai tersedianya pelayanan keperawatan profesional dalam pelayanan kesehatan (Gaffar, 1999).

Dari tabel 6 diketahui sebanyak 52\% responden tidak mengindikasikan adanya manfaat dalam meningkatkan skill praktek lapangan. Persepsi negatif ini dapat terjadi karena tidak selalu dalam keperawatan keluarga membutuhkan perawatan bersifat klinis tetapi lebih pada pencegahan primer dan pemberdayaan keluarga dalam keterlibatan perawatan anggota keluarga yang sakit. Perawatan dalam keluarga lebih mengedepankan penyelesaian masalah keluarga secara mandiri dan perawat sebagai vasilitator.

\section{KESIMPULAN DAN SARAN}

Berdasarkan pembahasan dapat disimpulkan bahwa persepsi mahasiswa terhadap empat indikator pemahaman 
manfaat asuhan keperawatan keluarga dan manfaat asuhan keperawatan keluarga terhadap peningkatan pengetahuan dengan prosentase $58 \%$ dan $65 \%$. Sedangkan dua indikator berdasarkan indikator skill dan manfaat asuhan keperwatan keluarga dalam meningkatkan skill praktek lapangan didapatkan persepsi negatif dengan prosentase masing-masing 55\% dan 52\%.

Saran yang dapat diberikan bagi pembimbing intitusi dengan memberikan pengarahan yang lebih intensif agar setiap mahasiswa mempunyai persepsi yang baik terhadap kompetensi skill yang dicapai dalam praktek asuhan keperawatan keluarga. Hasil penelitian ini dapat digunakan sebagai acuan untuk melakukan penelitian lanjutan dengan sampel yang lebih besar dan mengangkat masalah yang berkaitan dengan masalah profesi perawat yang belum dibahas dalam penelitian ini serta masih perlu untuk diadakan uji coba/validitas dan reabilitas terhadap alat ukur.

\section{DAFTAR PUSTAKA}

Effendy, N. 1998. Dasar-Dasar Keperawatan Kesehatan Masyarakat. Jakarta: EGC.

Friedman, M.M. 1998. Keperawatan Keluarga: Teori dan Praktik. Jakarta: EGC.

Gaffar, L.O.J. 1999. Pengantar Keperawatan Profesional. Jakarta: EGC.

Ismani, N. 2001. Etika Keperawatan. Jakarta: Widya Medika.

Khairudin, H.S.S. 1997. Sosiologi Keluarga. Yogyakarta: Liberty.

Notoadmodjo, S. 2007. Promosi Kesehatan dan Ilmu Perilaku. Jakarta: PT Rineka Cipta.

Notoadmodjo, S. 2003. Pengantar Pendidikan dan Ilmu Perilaku Kesehatan. Jakarta: Andi Offset.

Nursalam. 2002. Manajemen Keperawatan: Aplikasi dalam Praktik Keperawatan Profesional. Jakarta: Salemba Medika.
Nursalam., Pariani, S. 2001. Pendekatan Praktis Metodologi Riset Keperawatan. Jakarta: CV Sagung Seto.

Priharjo, R. 1995. Praktek Keperawatan Prof esional Konsep Dasar dan Hukum. Jakarta: EGC.

Su'adah. 2005. Sosiologi Keluarga. Malang: UMM Press.

Steven, P.J.M. 1999. Ilmu Keperawatan. Jilid 1. Jakarta: EGC.

Widatun, T.R. 1999. Ilmu Perilaku. Jakarta: CV Sagung Seto. 